\title{
Influencia del nivel educativo de padres y maestros en el aprendizaje de los niños de Maguey Blanco en el municipio de Ixmiquilpan
}

\author{
Esly Cuellar Hernández ${ }^{1}$ \\ Yuricela Ramírez Morales ${ }^{2}$ \\ Karen Chantal Ortiz Torres ${ }^{3}$ \\ Inés Margarita Simón Cano ${ }^{4}$ \\ Maestra: Margarita Bautista García \\ Planteamiento del problema
}

En los términos educativos, la formación de los alumnos se ha vuelto monótona y al parecer sin una trascendencia significativa dentro del concepto ser humano. Tal vez la globalización está afectando a nivel psique la forma en cómo se interpreta la realidad en los niños. Quizás la infancia se acortó, lo que impide que se concrete en muchos aspectos importantes la formación del individuo. Se pueden concluir miles de razones que están lastimando la infraestructura integral del sujeto, pero en realidad los cimientos de cualquier persona se dan en su entorno primario, que es el de la familia y la escuela.

La preocupación sobre cuál es la influencia en la educación de los niños por parte de la familia y la escuela, no es un tema actual, se ha indagado dentro de este rubro, pero al parecer todos los escritos son teorías que fomentan los "debería ser así... para que suceda esto", la realidad no aplica para sus determinaciones semánticas.

La importancia de la investigación a realizar, es analizar cómo está influyendo la preparación de los docentes y de los padres de familias dentro de las expectativas de formación que tienen sus alumnos o sus hijos, respectivamente. Es muy común encontrar patrones de repetición en el alcance de formación de los

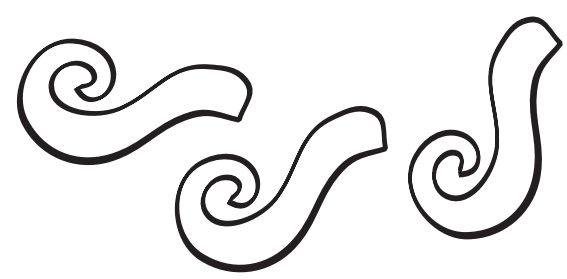

alumnos, es por ello que es importante que se estudie si estos patrones repetitivos están teniendo un alcance determinante.

\section{Justificación}

Por ejemplo, Bazán, Sánchez y Corral (2000) citados en Bazán, A; Sánchez, B, y; Castañeda, S. (2007), encontraron que la ayuda que los padres proporcionan a sus hijos en las tareas escolares predijo significativamente su desempeño al final del primer grado de primaria en una evaluación con cinco niveles funcionales jerárquicos de la lectura y la escritura de niños del noroeste mexicano. Con esto se quiere buscar más a fondo la influencia que tienen los padres de familia en la formación de los hijos. Uno de los supuestos que dan origen a esta investigación es, en qué medida la baja escolarización de los padres mina la eficacia en el proceso de escolarización de los educandos, sobre todo para que estos puedan aspirar a cursar grados de nivel superior en su formación académica.

El segundo supuesto es, cuál es el impacto que tiene la formación de los docentes en el proceso de los alumnos/as.

La función de guía y/o mediador del docente es fundamental cuando se promueven proce-

1 chelsi_wait0391@hotmail.com. Octavo semestre de la Licenciatura en Ciencias de la Educación, ULSA Pachuca. 2 yury.01_01@yahoo.com.mx. Octavo semestre de la Licenciatura en Ciencias de la Educación, ULSA Pachuca. 3 ot_karen@hotmail.com. Octavo semestre de la Licenciatura en Ciencias de la Educación, ULSA Pachuca. 4 margaritasimon92@gmail.com. Octavo semestre de la Licenciatura en Ciencias de la Educación, ULSA Pachuca. 


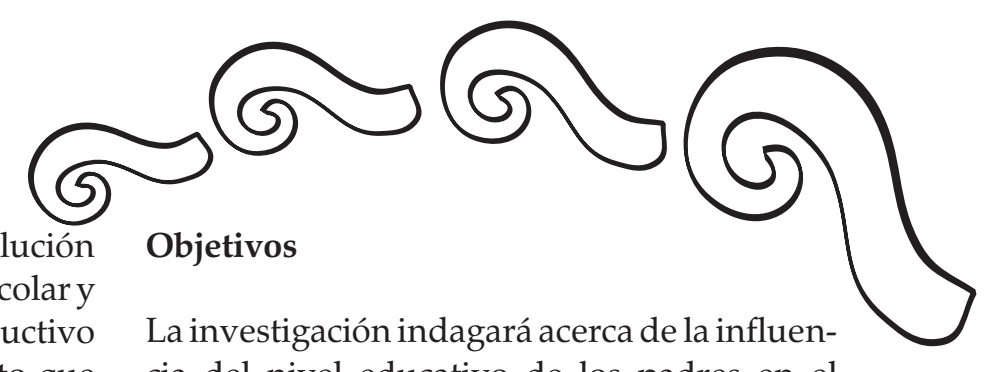

sos de crecimiento personal para la resolución de conflictos en el marco de la cultura escolar y se busca propiciar un cambio constructivo interno y autoestructurante. Es por esto que se quiere iniciar este proceso de investigación, para conocer en qué medida el educador impacta al alumno desde la intervención que como profesor tenga con los educandos y, no solo en la resolución de conflictos o en cuestiones meramente actitudinales, sino en cuestiones fundamentales como es la asimilación de contenidos, comprensión de temas y procedimientos que son esenciales de adquirir en la etapa en que se encuentren los alumnos. Dada la importancia que el profesor tiene en el proceso del educando, es necesario conocer y profundizar sobre la trascendencia que tiene que los profesores continuamente se estén actualizando, formando y preparando, puesto que las personas con quienes tratan, son seres cambiantes, que exigen estar a la altura de las necesidades que presentan y poder dar respuesta a ellas de una manera competente. Es necesario tener claro que de la preparación vasta y rica que se tenga como docentes, se podrá ayudar mejor a los alumnos a quienes se acompañará en su proceso de formación no solo académica sino como personas.

\section{Preguntas de investigación}

1. ¿Cuál es la influencia del nivel educativo de los padres de familia en el proceso de enseñanza y aprendizaje de sus hijos?

2. ¿En qué repercute la formación del docente en el proceso de enseñanza y aprendizaje de sus alumnos?

3. ¿Cómo conciben la educación los maestros de Maguey Blanco?

4. ¿Cuál es el contexto socioeconómico en el cual se desarrollan las familias de Maguey Blanco?

5. ¿Cuál es la metodología que usan los docentes en la planeación y práctica pedagógica?

cia del nivel educativo de los padres en el aprendizaje de sus hijos y otros factores que intervienen en el proceso de enseñanza y aprendizaje como la formación del docente y la forma en que conciben la educación, lo cual impacta en el salón de clases.

Objetivos específicos:

- Explorar la influencia del nivel educativo de los padres de familia en el proceso de enseñanza y aprendizaje de sus hijos en la comunidad de Maguey Blanco.

- Indagar en qué repercute la formación del docente en el proceso de enseñanza y aprendizaje de sus alumnos en la comunidad de Maguey Blanco.

- Averiguar cómo conciben la educación los maestros de Maguey Blanco.

- Describir el contexto socioeconómico en el cual se desarrollan las familias de Maguey Blanco.

- Explorar la metodología que usan los docentes en la planeación y práctica pedagógica de la comunidad de Maguey Blanco.

\section{Marco Histórico}

Dentro del Valle del Mezquital encontramos una historia llena de pasado, progreso y metas que han ido construyendo la identidad del pueblo otomí. Teodoro Manzano (1951) comienza a indagar fuertemente sobre la educación en el Valle del Mezquital, es considerado uno de los pioneros, su investigación fuerte se refirió a términos generales de la educación en Hidalgo, sin hacer énfasis alguno en su evolución, aun así sus investigaciones fueron el sustento para el trabajo que años después López, O. (2000) realizaría exclusivamente sobre el desarrollo de la educación, y el de Monroy, R. (2002) sobre educación primaria. La formación docente se considera que comenzó entre 1923 y 1935 donde se trabajaban dos escuelas normales rurales: Vite, 


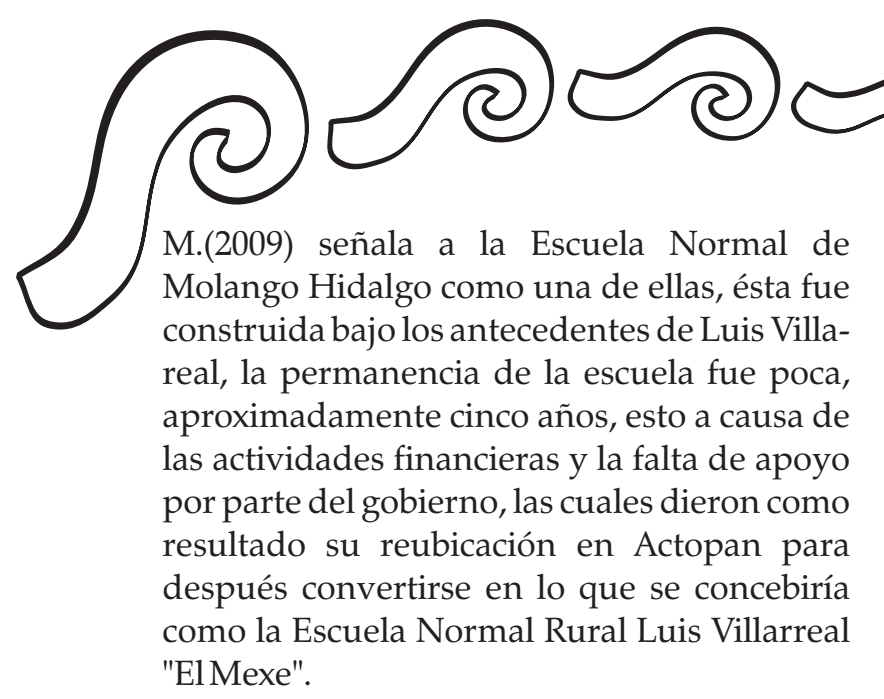

Por otra parte Serba, G. (2003) plantea que "la escuela Libre de Huejutla fue fundada en 1925 por gestiones del obispo de la región", esta escuela desapareció en 1935 por diversos factores, entre ellos se encuentran: la ordenanza estatal de 1926, que prohibió las escuelas confesionales, en 1935 se exigió erradicar las escuelas de índole religioso y se implementa una educación socialista. Serna (2002) considera que la educación formativa de docentes no comenzó con la fundación de las normales rurales, más bien en una investigación que realizó, se percató que la formación docente más antigua data de 1874, donde por más de cien se llevó a cabo la modalidad de género, es decir, su particularidad era que solo las mujeres tenían los conocimientos propios del género para educar.

Este tipo de educación se puede sustentar con las escuelas lancasterianas, que se consolidan el 22 de febrero de 1822, donde la educación se basa en el término enseñanza mutua. Con lo que respecta a la educación del alumnado, la escuela presentaba una estructura que homogeneizaba a los alumnos, ya que no se distinguía la edad, sino el conocimiento, se iba avanzando conforme el saber fuera superado (López, 2013). La formación docente estaba a cargo de las escuelas normales, pero no poseía la misma estructura que las actuales, en primera cabe recalcar, que un solo maestro era el que enseñaba a 200 alumnos (por ello la importancia de la educación mutua), la figura del docente era el de director y maestro con formación.
La escuela Lancasteriana también se implementó en los sectores privilegiados de la sociedad hidalguense (González, 2013), se aclara esto, ya que en los sectores rurales, el 99\% de su población eran analfabetas, el ejemplo es que en Maguey Blanco (comunidad del Valle del Mezquital), de una población de 30 personas solamente una persona sabía escribir (Maldonado, 2013).

Conforme pasó el tiempo, la educación exclusivamente en el Valle del Mezquital, fue progresando. Durante el Porfiriato, el lema de la educación porfirista fue la educación popular, en donde se comenzaron a dar a conocer los términos de obligatoriedad, uniformidad, gratuidad y laicidad. Por conversaciones con habitantes del lugar se reconoce que las escuelas llegaron antes que las carreteras - "yo recuerdo cuando nos íbamos caminando por el monte para llegar a la escuela" - expresa María de Jesús (2013), una habitante del Valle del Mezquital.

Las condiciones del Valle del Mezquital han sido precarias en muchos aspectos, los pueblos poco a poco son considerados comunidades y no espacios rurales, apenas en los últimos años, los altos índices de migración respaldan un desequilibrio en el aspecto educativo (Quezada, 2011).

Para poder conocer todos los datos sobre la educación en Hidalgo en 2008 y 2010 se llevaron encuentros sobre la Historia de la Educación en Hidalgo.

La historia de la educación y en particular del sistema educativo hidalguense se constituye en una herramienta de análisis para comprender los problemas pasados y actuales; además de una vista de las experiencias, aciertos y desaciertos en materia educativa. (Hernández, 2011)

La historia de la educación en Hidalgo se retoma y analiza desde la creación de Hidalgo como entidad federativa el 16 de enero de 1869, claro que la educación dentro del estado comenzó tiempo atrás. 


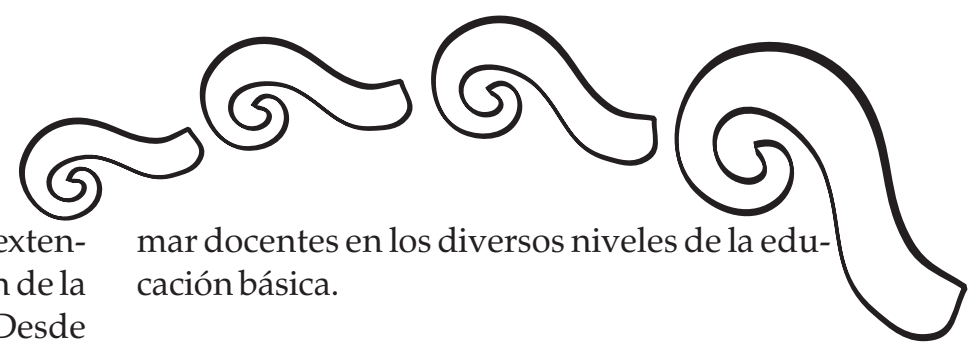

Uno de los mayores problemas que se extendieron recientemente fue la desaparición de la primera escuela normal rural el Mexe. Desde el punto de Osorio Chong, el estado "ya no necesita más maestros rurales", la desaparición del Mexe causó gran revuelo, de acuerdo con el II conteo de población y vivienda que se realizó en 2005 (época de la desaparición del Mexe) reveló que en Hidalgo existen 200 mil 194 personas mayores de 15 años que no saben leer ni escribir y la mayoría de estas personas se encuentran en comunidades indígenas y campesinas de la región, en donde se desenvolvían los egresados de las escuelas normales rurales. Tras la desaparición y los múltiples conflictos que desencadenó la desaparición de la escuela que hace 80 años fue fundada para el progreso y formación docente, surgió la Universidad Politécnica Francisco I. Madero, que actualmente sigue desempeñando su función dentro del estado como formadora de docentes en educación primaria, preescolar y educación física.

Ante la lucha contra las escuelas religiosas que formaban docentes, surgió la respuesta del socialismo en Hidalgo el 9 de Octubre de 1877, la Legislatura del estado expidió la primera ley de educación, donde se especificaba que en cada una de las cabeceras de distrito debía haber una escuela normal para maestros. A pesar de la imposición, el apartado de las escuelas normales quedó derogado en 1879, y la formación docente en el estado de Hidalgo fungió a cargo del gobernador, quien extendía los títulos de profesores de instrucción primaria a las personas que examinaban en el Instituto Científico y Literario. El 19 de junio de 1913 se planteó la iniciativa de la fundación oficial de la escuela Normal Francisco P. Olvera, secretario general del gobierno gestionó dicha propuesta y el día 2 de julio de 1913 se aprueba el proyecto para la fundación de esta escuela. Bajo esto, el 18 de julio del mismo año se inauguró la escuela normal coeducativa "Benito Juárez", lo que dio una nueva perspectiva a la formación docente; dicha escuela aún sigue presente bajo los términos de for-

\section{Marco conceptual.}

Dentro del ámbito educativo surgen varios actores que intervienen en este proceso, como son los padres de familia, los maestros y alumnos que juegan un papel importante, ya que en cada área tienen un lugar en la formación de los niños: los padres educan en valores a sus hijos para poder convivir en sociedad, dado que el hogar es el primer lugar de socialización y también son el apoyo para poder continuar sus estudios al tener en cuenta que la educación es una de las herramientas principales para la vida. Beltrán y Bueno Álvarez (1995) mencionan que si los padres tienen un nivel bajo cultural, se verá reflejado en su formación, esto sucede por la falta de motivación hacia los hijos y estos hacia los intereses escolares, en cambio si tienen un nivel alto, su actitud será favorable, ya que servirá como estimulación y concienciación para continuar con sus estudios.

Se puede aprender de todas formas, incluso sin escolarizarse, pero el nivel adquirido depende de múltiples factores, Herraiz (1999, p. 23) hace referencia que "el aprendizaje se refiere al cambio en la conducta o en el potencial de conducta de un sujeto en una situación dada como producto de sus repetidas experiencias en esa situación, siempre que el cambio conductual no pueda explicarse con base en sus tendencias de respuesta innatas, su maduración, o estados temporales". De acuerdo a este concepto, el aprendizaje requiere de experiencia, por tal motivo los padres y la escuela se convierten en los promotores del mismo.

Por otra parte, los maestros también tienen un impacto dentro y fuera del aula, ya que no solo enseñan materias, sino también ejemplos y actitudes que los alumnos aprenderán por imitación, Bandura (2000) le llama aprendizaje vicario y al respecto explica que dicho aprendi- 


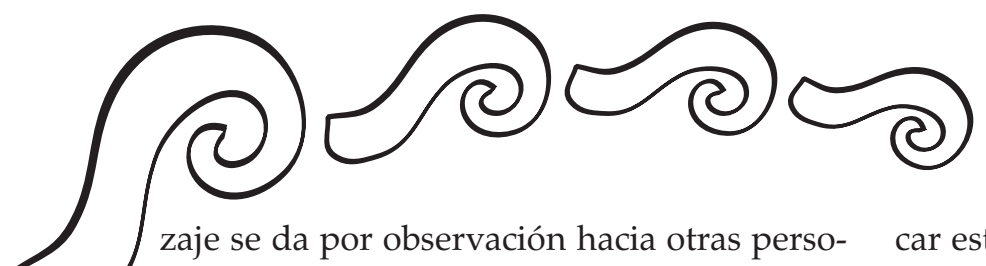

zaje se da por observación hacia otras persoconducta. Su teoría supone que la conducta y el aprendizaje son considerados como un resultado de diversas situaciones de refuerzo provenientes del medio.

"En un primer momento la importancia del aprendizaje observacional y concibe la conducta como resultado de la interacción de factores ambientales, personales y comportamentales. El comportamiento social obedece a una causalidad múltiple en la que además de factores externos y personales se incluyen los elementos cognoscitivos en forma de procesos simbólicos, se enfatiza la importancia del aprendizaje vicario, basados en el recuerdo de los efectos de las conductas de otras personas". (Pág. 47)

Otro concepto que debemos de considerar lo menciona Serrano (1996) en Rodríguez Sánchez, y Rojas de Chirinos (2008) acerca de la mediación desde la perspectiva cognitiva, la cual es concebida como:

“Un proceso integrador lógico que surge o se usa cuando se despliega una discordancia, un estado de incomodidad o una tensión producida por la afluencia de dos elementos cognoscitivos equivalentemente aceptados por el actor y que llevan a los sujetos afectados a realizar algún esfuerzo por devolver la consonancia." (Pág. 1).

Esto significa que el maestro actúa como mediador entre el conocimiento y el estudiante, lo que propicia desequilibrio cognitivo a partir de sus preguntas, y facilita la reflexión constante. La función que tiene el docente como mediador es indispensable, ya lo dicen Rodríguez Zúñiga y Guier (2002, p.67) “propicia una aproximación eficaz entre la información y el objeto de conocimiento y la adquisición de su aprendizaje por parte del alumnado". El maestro necesita de una ardua preparación ya que su tarea no es fácil, su formación es un punto principal el cual no se puede dejar de lado". Bower, y Hilgard (2000, p. 12) dicen que "la formación profesional es el sistema de capacitación que ha permitido y permite aplilas necesidades de formación inherentes al desarrollo de la actividad laboral." Torres (2013) que participa en la UNESCO menciona que:

El discurso de la profesionalización docente aparece prácticamente como omnipresente en nuestra vida docente: las autoridades educativas recurren a este discurso, los organismos internacionales lo hacen centro de sus recomendaciones, los medios de comunicación lo repiten, los padres lo exigen, las instituciones educativas se hacen eco, los sindicatos lo usan y repudian a la vez, etc. Por otra parte, este discurso también tiene que ver con los docentes que se forman y cómo impacta en esta formación.

Es importante tener en cuenta la formación de los docentes, pues son ellos los que se encargan de formar ciudadanos que serán parte de una sociedad que se desenvolverá en diferentes ámbitos que afectarán la economía, entre otros.

De igual manera Bower, G. et.al. (2000, p. 16) hablan acerca de la importancia de formar al formador, la cual es "dar ocasión, a los conductores de procesos de aprendizaje, conocer, descubrir, aplicar y valorar métodos y técnicas para su crecimiento personal y profesional", por esta razón se le exige al docente cumplir con diez competencias básicas (Generales) que Candreva y Susacasa (2009) exponen que debe manejar en el aula de clases: responsabilidad, autoconfianza, conciencia, valores éticos, habilidades comunicativas, comunicación interpersonal, flexibilidad, trabajo en equipo, iniciativa, planificación, innovación/creatividad. Cada una de estas competencias ayudará a mejorar la práctica docente y a responder a las necesidades que los alumnos tienen debido a la falta de responsabilidad actual de los padres, puesto que la escuela debe responder e intentar cubrir esos espacios en los cuales los niños necesitan ser suplidos y entendidos al dar el mejor servicio posible por parte de los docentes. 


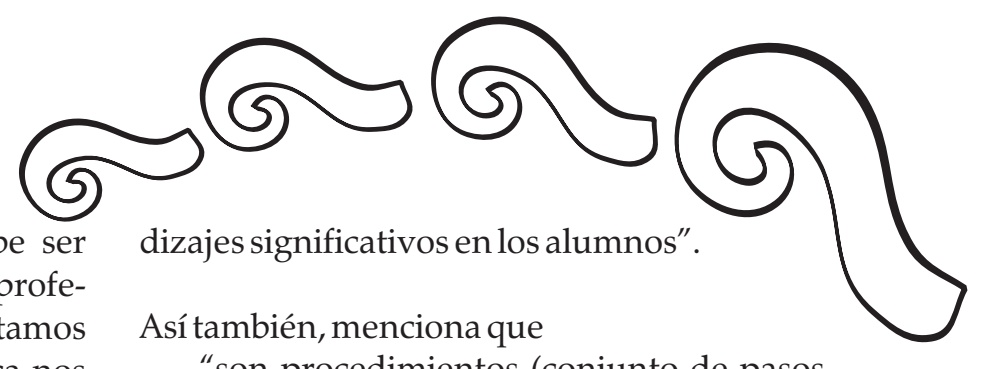

La formación del ser humano no debe ser únicamente considerado en el ámbito profesional, debe tomarse en cuenta que estamos expuestos a constantes cambios y nunca nos dejamos de formar, al igual que la educación que no es un fenómeno estático, por lo cual el docente requiere de actualizaciones que favorezcan su práctica. En la educación formal algunos de los actores principales son el alumno y el maestro, éste aprende cada vez que enseña y es un constante proceso que se da y enriquece a ambas partes. El maestro debe tener en cuenta la capacidad cognitiva del alumno para facilitar su aprendizaje y que le sea significativo, por lo que debe adecuar los contenidos y crear un ambiente propicio.

Salvador menciona (1988) que el aprendizaje significativo

"es un instrumento potencialmente útil y valioso para el análisis y la reflexión psicopedagógica. Sin embargo, para que pueda desempeñar adecuadamente este papel, es necesario despojar de muchas de las connotaciones que ha ido acumulando de forma subrepticia y, al mismo tiempo, desarrollar otras que hasta el momento han sido escasamente tomadas en consideración." (Pág. 131)

El aprendizaje significativo tiene una postura actual que se está trabajando a nivel mundial y se clasifica dentro del enfoque constructivista; México no está exento, ya que es pilar de los planes y programas curriculares, que tienen por finalidad que el alumno construya su conocimiento a partir de proyectos que llevan a cabo durante el ciclo escolar, por lo que encuentran la relación entre el conocimiento adquirido y la vida cotidiana, es decir, su aplicación en diferentes contextos.

Para propiciar el aprendizaje significativo dentro del proceso de enseñanza y aprendizaje se requiere trabajar con estrategias;, Díaz Barriga, (2002, p. 21) nos dice al respecto que las estrategias son "procedimientos que el agente de enseñanza utiliza en forma reflexiva y flexible para promover el logro de aprenoperaciones o habilidades) que un aprendiz emplea en forma consciente, controlada e intencional como instrumentos flexibles para aprender significativamente y solucionar problemas".

Campos explica:

Son una serie de operaciones cognitivas que el estudiante lleva a cabo para organizar, integrar y elaborar información y pueden entenderse como procesos o secuencias de actividades que sirven de base a la realización de tareas intelectuales y que se eligen con el propósito de facilitar la construcción, permanencia y transferencia de la información o conocimientos. (Campos, 2000.p.2)

Se considera entonces que el proceso de enseñanza/aprendizaje se integra y desarrolla con estrategias, que conllevan a una constante reflexión en los actores. Del alumno es necesario saber su condición actual, sus habilidades, conductas, destrezas, y solo a partir de eso plantear lo que se quiere lograr, el tipo de metodología, los materiales didácticos, objetivos, fijar metas claras y finalmente formas de evaluación que servirán como estándar del cumplimiento de los objetivos planteados.

\section{Marco Teórico}

"La enseñanza es buena solo cuando es previa al desarrollo" Lev Vygotsky.

La mediación, desde la perspectiva cognitiva, es concebida por Serrano (1996), como:

Un proceso integrador lógico que surge o se usa cuando se despliega una discordancia, un estado de incomodidad o una tensión producida por la afluencia de dos elementos cognoscitivos equivalentemente aceptados por el actor y que llevan a los sujetos afectados a realizar algún esfuerzo por devolver la consonancia.

Los teóricos cognoscitivistas como a Bruner (1960), Gagné, (1974, 1975, 1985) y Ausubel 


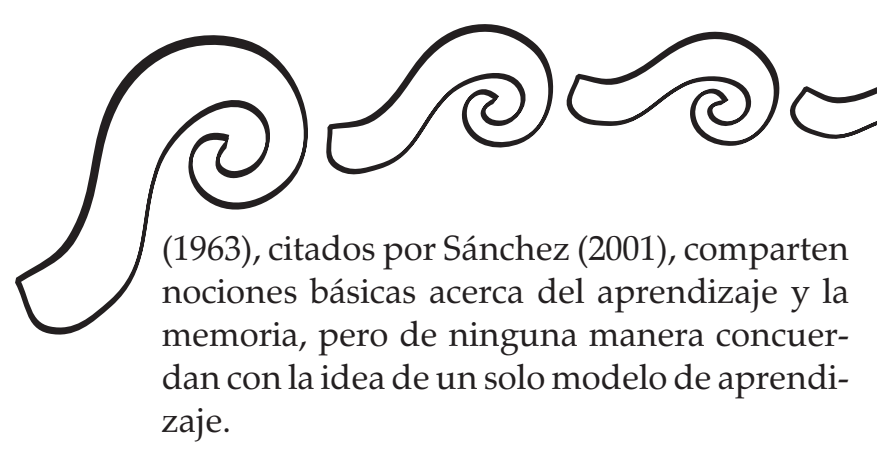

$\mathrm{Al}$ respecto, consideran que el aprendizaje es el resultado de nuestros intentos por darle sentido al mundo y para esto, el individuo usa todas sus herramientas mentales. La forma en que pensamos acerca de las situaciones, además de nuestras creencias, expectativas y sentimientos, influyen en lo que aprendemos y en cómo lo aprendemos.

Esta tendencia va en oposición al aprendizaje sin sentido, memorístico o mecánico. Según los autores, si el individuo tiene conceptos relevantes, adecuados e inclusivos, claros y disponibles en su estructura cognitiva, nuevas ideas e informaciones podrán ser aprendidas y retenidas. Los primeros conceptos servirán de anclaje a otros nuevos y el aprendizaje así adquirido se dice significativo lo que constituye el mejor mecanismo humano para adquirir y retener informaciones de un cuerpo de conocimientos.

Bandura (1977) y Kelly (1978), citados por Sánchez (2001), generan una semejanza entre la conducta intencional cotidiana del hombre y la labor del científico. Tanto uno como el otro, se encuentran inmersos en un proceso de observación, interpretación, predicción y control. Cada persona construye para sí un modelo representativo del mundo, que le permite diseñar el curso de su conducta en relación con dicho mundo.

Este modelo está sujeto a cambios a través del tiempo, ya que las construcciones de la realidad son constantemente sometidas a prueba $\mathrm{y}$, eventualmente, modificadas para permitir mejores predicciones en el futuro. De este modo el cuestionamiento, la exploración, la revisión y reemplazo a la luz del fracaso predictivo, característico de la teorización científica, es precisamente lo que el hombre común realiza en sus intentos por anticipar los eventos (Pope, citado por Picón 1992).

Bandura, Adams y Beyer (1977), citados por Sánchez (2001), ilustran el aprendizaje en el individuo desde una perspectiva amplia que ellos han designado como concepción cognitiva social. El comportamiento humano se explica mediante un modelo de reciprocidad triádica en el que la conducta, los factores personales, cognitivos y de otro tipo, y los acontecimientos ambientales actúan entre sí como determinantes interactivos.

Vygotsky (1997) plantea que para conocer el desarrollo del niño, es necesario comprobar primero el nivel efectivo y real, que consiste en el "nivel de desarrollo de las funciones psicointelectivas que ha conseguido como resultado de un específico proceso de desarrollo, ya realizado. Luego se analiza el nivel de zona de desarrollo próximo o potencial, que genera un adelanto que cambia los procesos intelectuales del individuo.

La Teoría Constructivista Social de Mediación de Vygostky (1997), pone énfasis en los mecanismos de influencia educativa donde la dimensión social del aprendizaje es un aspecto esencial para el autor. Considera que los alumnos construyen el conocimiento individualmente, pero al mismo tiempo junto con otros. La ayuda de los otros, cumple una función socializadora. Este proceso de socialización personal permitirá formar personas, similares a los demás, pero al mismo tiempo, diferentes.

En el gráfico 1 se ilustra las ideas esenciales de la teoría sociocultural de Vygotsky. El autor postula que al establecer relaciones interpersonales con los agentes mediadores, el ser humano desarrolla los procesos psicológicos superiores, lo cual implica que a través de la educación se promueve el desarrollo individual de los miembros del grupo y la asimilación y producción de la cultura del grupo. 


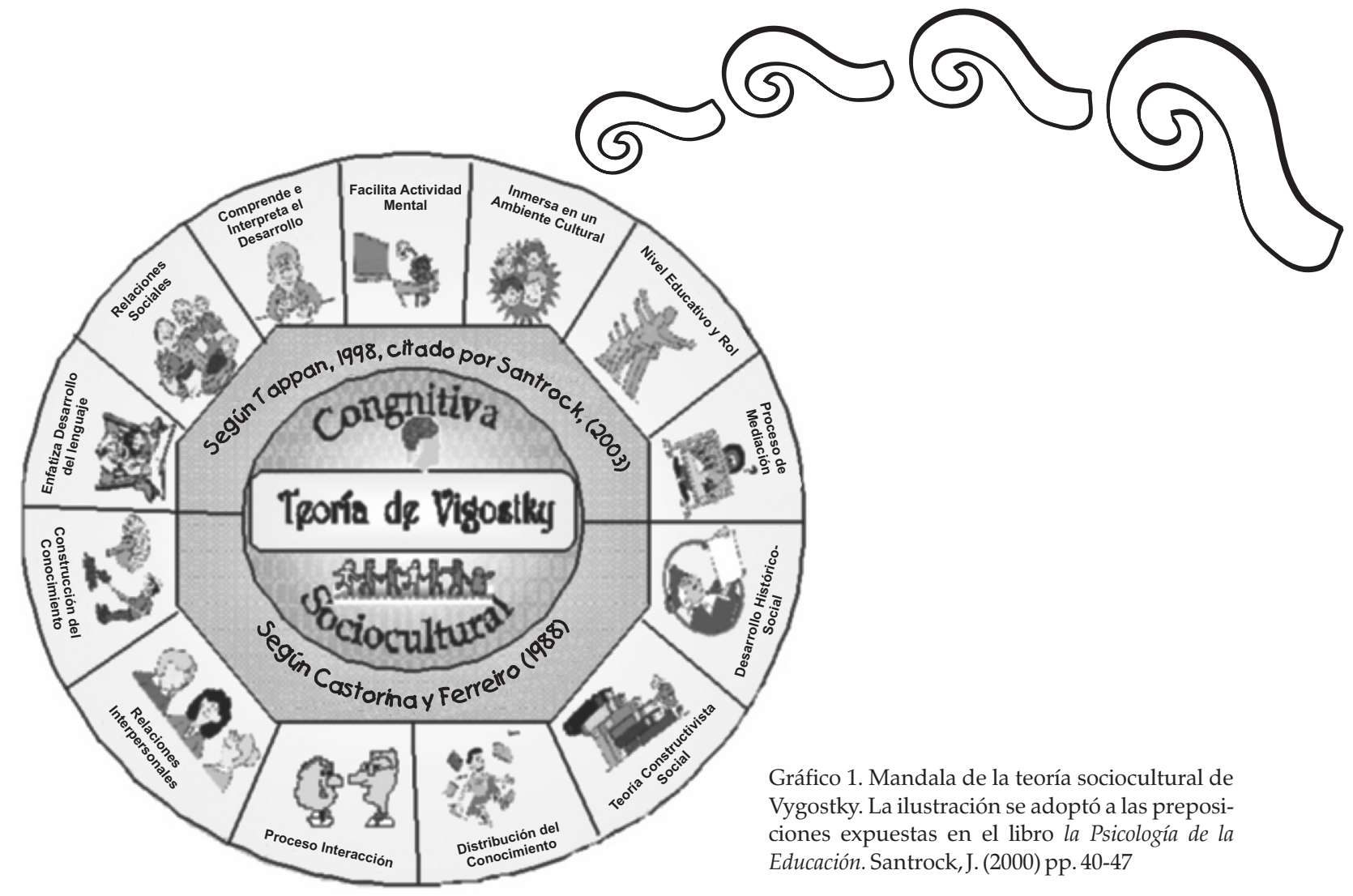

El modelo de mediación que se ha mencionado en las últimas décadas se encuentra vinculado con el término acompañamiento:

Meuler (1988), sostiene que quien se deja acompañar sabe a dónde quiere ir, aunque haya pausas y rodeos.

El acompañamiento en educación se afirma que es exitoso únicamente cuando el maestro se mantiene abierto para aprender de los encuentros y vivencias y que solo se transforman en experiencias gracias a la reflexión. Por lo tanto, el acompañamiento debe acreditarse en forma práctica, de modo permanente y de una manera reconocible y criticable. Desde esta perspectiva se concibe al maestro como un aprendiz experimentado, quien en muchos aspectos, tiene todavía que progresar y por ello tiene comprensión frente a los intereses de aprendizaje de sus alumnos y puede aportar experiencias sin imponerlas.

El proceso de enseñanza y aprendizaje de los alumnos necesita de alguien que los guíe, a lo que se le denomina mediador.

El concepto de mediador y de aprendizaje mediado tiene su origen en la Teoría Sociocultural de Lev Vygotsky (1934), la cual operacionaliza a través de la llamada Zona de Desarrollo Potencial una forma de lograr aprendizajes duraderos y el desarrollo óptimo de un estudiante con la ayuda de los adultos o de otros estudiantes más avanzados.

Esta teoría trata de explicar que el profesor es el que actúa como mediador en el aprendizaje de los alumnos ya que permite una evolución en sus capacidades.

Es por esto que que el profesor tiene que cumplir con ciertos aspectos para que su tarea sea más eficaz.

Las aportaciones de Brophy y Good (1986) sobre la <<eficacia del profesor $>>$ las recogemos a continuación:

1) La cantidad de aprendizaje y el ritmo dela instrucción.

2) Agrupamiento: clase total y grupo pequeño.

3) Suministrar información.

4) Preguntar a los alumnos. 


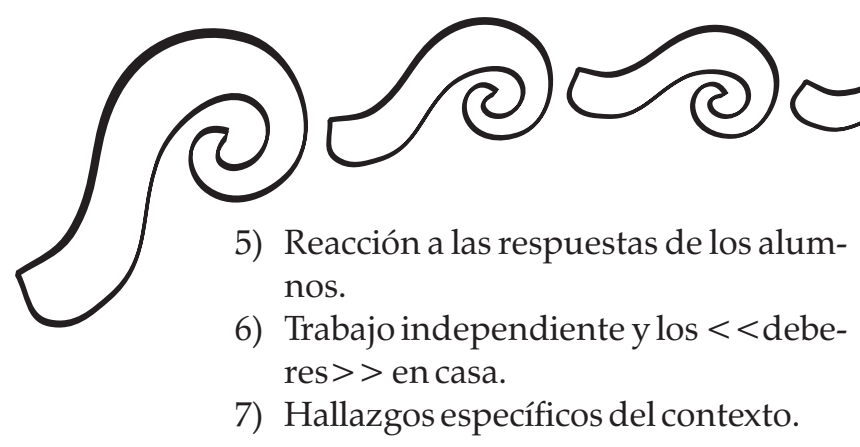

Otra manera realista de encontrar relación con la eficacia de la enseñanza consiste en conjugar el estilo del profesor con el del estudiante:

Heil y Cols,(1960) relacionan tres estilos de profesores - espontáneos o vitales; sistemáticos u organizados; temerosos o inseguros - con tres estilos de alumnos: luchadores o de alta motivación de logro; dóciles o conformistas; negativistas o críticos con la autoridad. Los profesores a su vez se dividían en cálidos y fríos.

Es por esto que el profesor constituye una de las variables más importantes del proceso de aprendizaje, debe ser capaz de presentar y organizar la materia de estudio, explicar las ideas y de manipular las variables que afectan al aprendizaje.

Aparte de la mediación del padre, se encuentran los modelos de conducta parental, es decir, el estilo educador que los padres muestran hacia sus hijos. Existen algunos acercamientos empíricos cuya finalidad ha sido la construcción de modelos teórico-explicativos de la conducta educadora de los padres (Baldwin y cols., 1945; Roff, 1949; y Jenkis , 1959).

Una de las principales conclusiones de estos modelos teóricos es que la conducta de los padres no es multidimensional, y que tampoco consiste simplemente en variaciones a lo largo de un solo eje; estos modelos son:

\section{Modelo de Schaeffer:}

Se refiere únicamente a la conducta maternal. Para su elaboración el autor se apoya en observaciones de la conducta de interacción en grupos de madres con sus hijos y en los datos recopilados mediante entrevistas (Hernández, 2002).

\section{Modelo de Becker}

Se trata de un modelo tridimensional que incluye, además de las dimensiones de "afecto versus hostilidad" y "restrictividad versus permisividad", una tercera dimensión referida al compromiso "emocional-ansioso versus despegado-tranquilo".

\section{Marco referencial}

El motivo que nos ocupa en este trabajo es conocer cómo influye la escolarización de los padres de familia en la formación de los alumnos, así como la influencia e importancia de la formación del docente en la vida escolar de los educandos de primaria.

Algunas investigaciones nos ayudan a sustentar con respecto a casos concretos sobre el tema.

Para la formación de docentes es importante mencionar la fuerza que actualmente está teniendo este aspecto del ámbito educativo. De acuerdo a lo que la reforma educativa 2013 hace referencia, el papel del docente recobra un sentido medular en la educación de México, para que esta formación pueda tener validez es necesario conocer cuán capacitados están los maestros para que a partir de dicha evaluación se puedan aplicar medidas para capacitar a los docentes en las áreas que se encuentran rezagados.

López, (1999), citado en (Aldo Bazán, A; Zavala, M; López, M y, Barona, C. 2005) explican la importancia de la formación inicial de los maestros:

Si bien es cierto que es importante la formación inicial de los maestros, la actualización de los maestros en servicio es primordial en el mejoramiento del nivel académico de los estudiantes, y para lograr un desarrollo profesional del maestro que le permita tener una carrera profesional satisfactoria.

Con esto consideramos que, para que un docente pueda tener las herramientas necesa- 


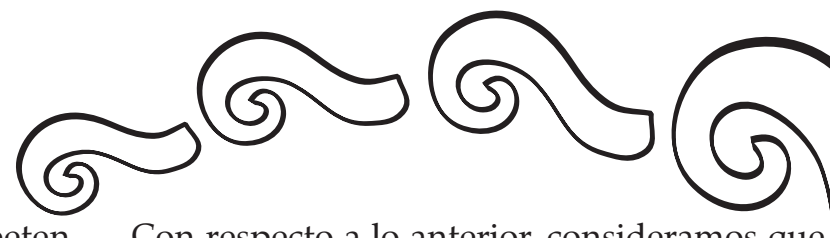

rias para desempeñar su labor con competencia, y no solo las intelectuales sino aquellas que necesita para acompañar de una manera completa e integrada a sus alumnos, no basta con haber terminado la carrera sino que se considera que la actualización es un medio para continuar creciendo y formándose.

Bazán, et.al. (2005), mencionan en un estudio realizado en Estados Unidos, mismo que fue reportado por Jilkins (2001) que

"cuando los maestros se familiarizaron plenamente y aplicaron un programa de enseñanza/aprendizaje en su planeación diaria y desarrollo instruccional, el aprendizaje de los niños se incrementó de manera notable en un programa de intervención de 12 semanas, con seis evaluaciones en lectura y escritura durante el proceso de intervención".

Vemos cómo la formación docente es de suma trascendencia, al mismo tiempo que se dispone para aplicar los elementos teóricos a su labor docente, el desempeño que cada maestro tenga en el aula depende de todo aquello que haya adquirido durante su formación. Dicha tarea o labor es tan importante y esencial en la vida del educando, que todo aquello que haga o deje de hacer, lo que implemente o deje de lado tenga un gran impacto.

Otro de los aspectos en este trabajo investigativo es el sector familiar, sobre todo el de los padres de familia. Es este un sector que influye de manera directa en la formación de los hijos.

Según una investigación realizada por Yárnoz, (2006) da a conocer lo siguiente:

"La importancia del rol del padre ha sido evaluada de forma típica mediante el impacto de su ausencia en el desarrollo del niño. Diversos estudios constataron los efectos adversos de la ausencia paterna sobre el desarrollo socioemocional y cognitivo de los niños cuando ésta comenzaba antes de los cinco años".

Con respecto a lo anterior, consideramos que los padres de familia marcan de manera esencial a los hijos, sobre todo en la infancia el padre de familia juega un papel fundamental. Gracias a los diferentes estudios realizados Bazán (2007) et.al. es que cobra sentido adentrarnos al estudio de este sector, el papel de los padres de familia.

Ya que hacen mención que muchas veces el apoyo que los padres de familia brindan a sus hijos/as está mediado por aquello que traen y que les marcó de sus historias de vida, del grado de escolarización que estos alcanzaron, de lo que como padres esperan del aprendizaje, de las ocupaciones que estos tengan, etc.

Por tanto, cabe señalar que toda la experiencia que haya marcado a los padres de familia en su momento, mientras estos estaban en etapa de escolarización, el apoyo que, a su vez hayan recibido de sus padres, marcará igualmente a sus hijos, es de esta manera que se cae en un círculo vicioso: los padres fueron educados de una manera, a la vez que lo fueron los padres de estos y así sucesivamente. Todo influye en el educando que cada día reciben los docentes en su clase. Es con toda esa carga histórica de la familia, de lo social, etc., con la que se enfrenta.

Es importante resaltar que si el proceso educativo tiene que ver con diferentes factores como sociales, familiares, preparación, entre muchos otros, no solo compete a los docentes lidiar con todos ellos sino también a los padres, que en la actualidad están tendiendo a deslindarse de dicha responsabilidad para delegarla a la escuela. Es el estudiante quien afrontará las consecuencias y a quien le tocará cargar con el peso de la mala o buena formación de los docentes y de cuán competente sea la escolarización que hayan tenido sus padres.

De acuerdo a Matute, Sanz, Rossellu y Ardila (2007) en sus investigaciones dan a conocer que

"la variable medio/ambiental importante 


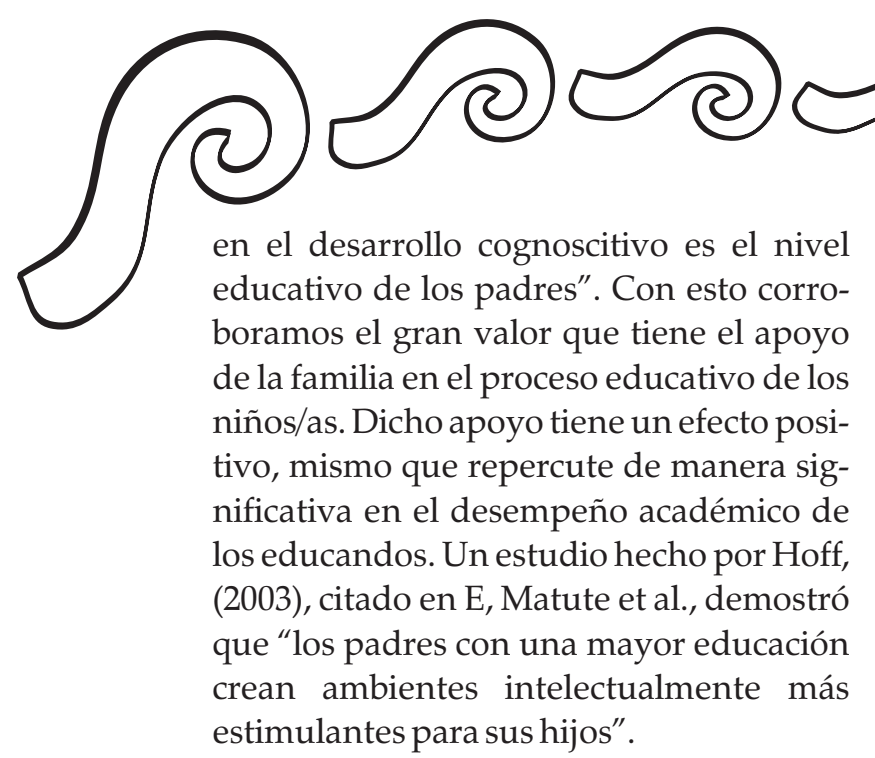

La realidad del educando actual presenta grandes necesidades, en muchos casos la escuela solo se remite a llenarle de contenidos el intelecto y deja rezagada así la parte emocional y otras áreas que conforman a la persona.

$\mathrm{Al}$ recordar la frase "el niño no es una botella que hay que llenar sino un fuego que es preciso encender", se puede entender cuál ha de ser la función esperanzadora tanto del profesor en la escuela como la del padre de familia en casa. Claro está, que es necesario que ambos entiendan el proceso formativo de los niños e incidir de forma asertiva, sin limitarlos a un contexto o a una forma de vida principalmente para aspirar a ir más allá de sí mismos.

\section{Población}

La investigación se hizo en la escuela Juan de la Barrera de nivel básico, en la comunidad de Maguey Blanco con los maestros, alumnos y padres de familia de los grupos de $4^{\circ}$ y $6^{\circ}$ grados, ya que son representativos de un proceso de aprendizaje.

\section{Supuestos}

La formación de los docentes tiene un impacto en las estrategias que implementan para la enseñanza y aprendizaje de sus alumnos.

El grado de escolarización de los padres de familia influye de manera significativa en la motivación de sus hijos para estudiar.

\section{Bitácora}

\section{2 de noviembre de 2013, Martes:}

El frente frío nos acompañó desde la espera para salir de la Universidad La Salle Pachuca aproximadamente a las seis de la tarde y la oscuridad devoró rápidamente la claridad de un cielo gris. Después de aproximadamente dos meses trabajando en la elaboración de marcos teóricos, elaboración de material didáctico, entrevistas e instrumentos de observación, a las 6:30 salimos rumbo a la comunidad de Maguey Blanco en el municipio de Ixmiquilpan.

La noche gobernó durante todo el camino y la lluvia nos acompañó en el trayecto, aproximadamente 1 hora con 20 min. llegamos al pueblo donde nos hospedaríamos para trabajar los siguientes tres días. Comenzamos este proceso de investigación, desde elaborar la parte teórica que conforma dicho proceso, preparar los materiales, mismos que utilizaríamos al insertarnos en la comunidad que sería nuestro campo de investigación.

Por la tarde salimos de la ciudad de Pachuca, rumbo a la comunidad de Ixmiquilpan, Hgo., en esta estaríamos hospedadas para proseguir con el proceso de investigación cualitativa.

\section{Miércoles 13 de noviembre de 2013:}

Llegamos a la escuela primaria Teniente Juan de la Barrera a las 9:00 am. Pasamos al departamento de dirección de la escuela, la directora nos recibió con disposición, sentimos que la acogida fue muy buena, el trato fue muy amable, con apertura y sobre todo, con mucha liberalidad, para dejar que nosotras tomáramos el espacio como nuestro. Posterior a la presentación con las autoridades de la escuela proseguimos a conocer los grupos de cuarto grado de primaria, para esto las alumnas de 5to semestre de la licenciatura en Ciencias de la Educación organizamos a los alumnos para que se presentaran, que dijeran su nombre, lo que más les gustaba hacer, su comida favorita. Posteriormente salimos al patio para jugar a 


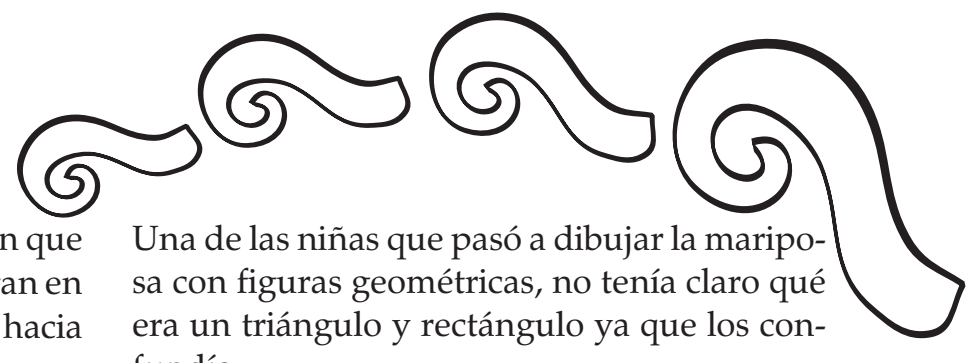

"La ardilla dormilona", el cual consiste en que los alumnos formen un círculo y se pongan en posición con una mano afuera y otra hacia adentro. Otro niño que es elegido por la persona quien dirige la actividad, lleva una nuez en la mano, éste camina alrededor del círculo, mientras los otros cierran sus ojos y están a la expectativa de que el niño que lleva la nuez los elija para colocar la nuez en la mano que está hacia afuera y así competir con éste por el lugar que queda vacío, gana quien llegue primero.

Otra actividad fue "Doña Blanca", la cual consiste en que los niños forman un círculo, se eligen dos personas, en este caso los niños, una que represente a doña Blanca y un niño que represente al jicotillo. El que representa al jicotillo tiene que atrapar a doña Blanca, mientras se canta la canción propia de la ronda.

A continuación nos fuimos al salón, ahí se continuó con la actividad en la que los niños formaron equipos, estos recibieron un trozo de papel que contenía el título con el nombre de algún personaje, ellos se organizaron para que un integrante del equipo pasara a representar al personaje haciéndolo con mímica, mientras que los demás alumnos tenían que adivinar de qué personaje se trataba.

Llegó la hora del recreo y los niños salieron para tomar el desayuno, nosotras nos integramos a éste, la mamá de una de las alumnas del equipo de investigación nos invitó el desayuno.

Después del recreo nos integramos con el grupo de cuarto "B", con ellos salimos igualmente al patio para realizar algunos juegos.

Una de estas actividades fue, el juego del "pastel partido", misma que consiste en que los alumnos formen un círculo, luego dos de los niños se toman de las manos y dan vuelta alrededor del círculo, estos eligen a otra pareja para dar un toque en las manos de estos que están en el círculo, después tienen que correr.

Trabajaron actividades que favorecieron la integración de los alumnos y sobre todo, de las alumnas responsables de la investigación con los alumnos que conforman la población a investigar; algunas de estas actividades fueron: presentación de las alumnas de 5to semestre de educación con la profesora responsable del grupo.

\section{Jueves 14 de noviembre de 2013}

Muy temprano, la mañana nos regaló la vista del cielo totalmente azul, transcurrieron los minutos y el sol se posó en lo más alto del cielo totalmente despejado, increíblemente un giro climático le dio más vida al lugar en donde estábamos recibiendo la luz de un nuevo día.

El desayuno estaba sobre la mesa y a pesar de la hora y el sol deslumbrando, nuestros rostros denotaba cansancio, no sé si es el pesado cambio climático o el alma que añora lentamente el confort de la dulce sonrisa de nuestras madres. El desayuno fue ligero y aproximadamente a las 8:35 alistamos nuestras planeaciones, materiales, actitud y sonrisas para ir a la escuela nuevamente.

En el camino la actitud de todas se transformó y el clima de cansancio desapareció completamente, llenas de energía y buena vibra entramos nuevamente a la primaria Teniente Juan de la Barrera.

En esta ocasión se dividió el grupo en dos partes, el $4^{\circ}$ "A" fue guiado por Yury, Chantal y la Miss Margarita, por otro lado el $4^{\circ \prime} \mathrm{B}^{\prime \prime}$ estuvo bajo la batuta de Esly y Margarita.

Al entrar al salón el silencio gobernaba totalmente el aula, el $4^{\circ \prime} \mathrm{B}$ " suele ser muy callado, ordenado y atento a seguir órdenes, su maestra se levantó para saludarnos. Alegremente nuestros rostros se iluminaron al ver esos 


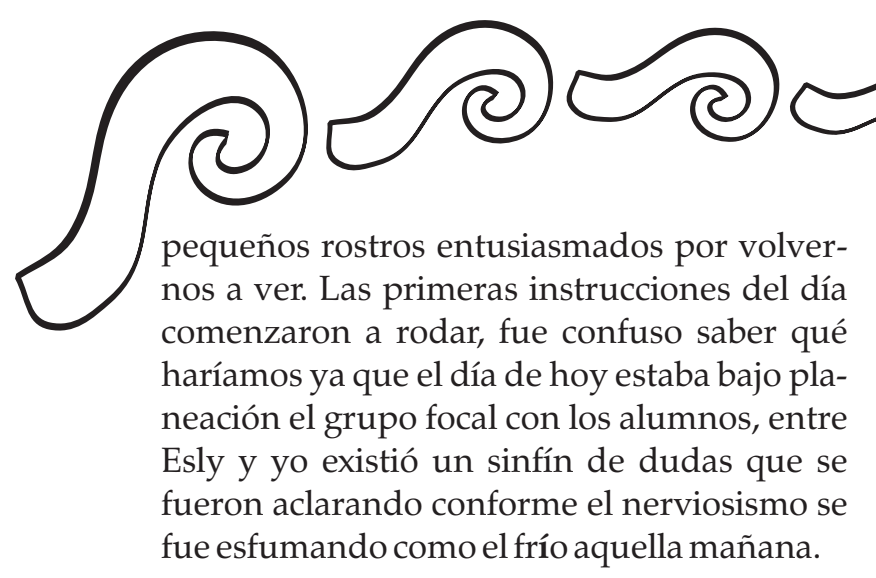

Solicitamos a los alumnos que formaran un gran círculo, la primera actividad se llamó "el cartero", esta actividad se hizo para que los niños se divirtieran un poco antes de comenzar el asunto serio. Son esas risas tan desmesuradas que alimentan el alma de un adulto, esa forma tan inocente de sonreír por el simple hecho de hacerlo es lo mágico y enigmático en la infancia. En lo personal adoré que el silencio no gobernara el aula. Después de aproximadamente cuatro rondas, comenzamos el grupo focal. Esly tomó la batuta en esta actividad y les dio las instrucciones sobre lo que se iba a realizar, les mencionó que serían grabados, tal vez este aspecto intimidó a los pequeños al hablar, pero aun así los más extrovertidos salieron a relucir.

No todas las respuestas parecían coherentes y en ocasiones el bullicio interrumpía la dinámica. Entre tantas preguntas y tantas pequeñas voces que contestaban sensatos a su realidad, hubo una que a pesar del bajo volumen de su sublime voz, hizo eco en todo nuestro interior, Esly preguntaba: ¿Qué les gustaría que les dijeran sus padres? Tímido, cabizbajo y entre hombros contestó: que me diga que algo de lo que hago está bien. Tal vez el salón no guardó silencio ante su temblorosa respuesta, pero enciendo una vela en sus ojos de esperanza de algún día llegar a satisfacer a sus padres. Tal vez no fue la oración y mucho menos la complejidad de la sintaxis, fue la mirada perdida, los ojos brillosos y el tono bajo lo que hizo que toda nuestra alma se desmoronara.

Es esa impotencia que va gobernando nuestras almas al escuchar la ansiosa necesidad de los niños porque sus padres acaricien su rostro y con un beso en la frente les digan que los aman, eso fue lo que despertó en nosotras esos rostros tan sonrientes ansiosos de ser amados. Asimismo, otra pregunta que revivió la alegría de los pequeños fue la de ¿Qué quieres ser de grande? Todas las manos arriba ansiosas de ser tomadas en cuenta, muchos dijeron querer ser: periodistas, médicos, maestros, arquitectos, veterinarios y soldados, una vez más una voz tímida levanto su rostro hacia mí y exclamó: yo quiero ser albañil. Me causó un gran interés no solo su respuesta sino su esencia y su mirada, exclusivamente me acerque a él, pregunté en: ¿en qué trabajan tus papás? Jamás olvidaré su rostro lleno de orgullo y sin bajar la mirada su mirada se clavó a la mía y exclamó: mi mamá vende elotes en las escuelas y mi papá es albañil, construye edificios. Su sonrisa acompañó el tono de jactación de sus palabras, después le pregunté -itú le ayudas a tus papás en su trabajo?- nuevamente el brillo de sus ojos se intensificó y me dijo -sí, le ayudo a mi mamá en vender elotes en las escuelas, pero me gusta más ayudarle a mi papá, luego barro el cemento que se cae y pronto me va a enseñar a hacer la mezcla, yo quiero ser como él-, fue en ese momento cuando me pregunté totalmente qué es lo que en realidad hace feliz a un niño, no es el dinero, ni siquiera los juguetes, para ese niño sus padres lo hacían feliz, estar con ellos, no necesitaba más que estar a su lado, su cercanía, su calor y su esfuerzo, son esas pequeñas simplezas de la vida que hacen a las personas verdaderos seres humanos.

Al terminar las diez preguntas, formamos la fila de las niñas y de los niños y subimos a la cancha de educación física a jugar una vez más. Doña Blanca volvió a tener vida y "el quijote saltarín" recobró la fuerza de las sonrisas de esos niños, aproximadamente 10 minutos jugamos y volvimos al salón para que ellos salieran al recreo.

$\mathrm{Al}$ salir al recreo unas pequeñas niñas de $4^{\circ}$ " $\mathrm{A}$ " nos repartieron unas loterías para que jugáramos, entre palomitas y risas pasamos el recreo. A las 11:00 horas organizamos todo para nues- 


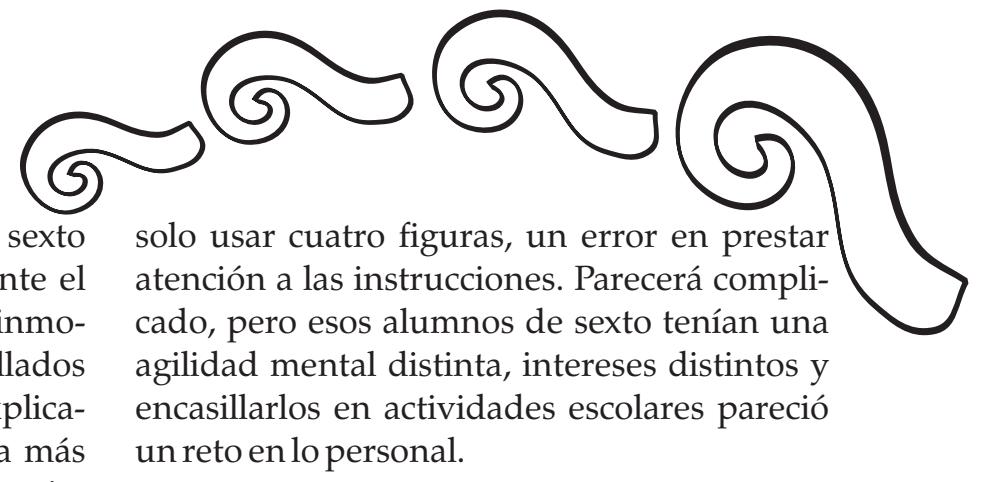

tro primer encuentro con los grupos de sexto año, el primero fue el $6^{\circ}$ " $\mathrm{B}$ ", literalmente el orden gobierna ese salón, total silencio, inmovilidad por parte de los alumnos, callados escuchaban a la maestra, atentos a su explicación, cuando llegamos, el silencio hacía más ruido que los propios niños, la miss Margarita se encargó de hacer la entrevista a la profesora Vicky. La primera actividad que realizamos estuvo bajo el mando de Yury, es complicado interpretar las respuestas de los alumnos, ya que puede ser por nervios o en realidad no sabían lo que era un polígono, a pesar de ello la lluvia de ideas que hizo mi compañera nos ayudó a comprender un poco más sobre los conocimientos previos que tenían sobre el tema.

La competencia de dibujar con polígonos se llevó a cabo en un dinámica bastante ordenada, pareciera que nos les emocionaba tanto, conforme fueron tomando confianza los alumnos comenzaron a pintar en sus rostros sonrisas y expectativas sobre el juego. Al finalizar continuamos con la actividad de contar historias, fue una experiencia divertida ya que los alumnos de este grupo plasmaron en sus oraciones emociones, experiencias y sentimientos por los que estaban pasando, la historia fue bastante recurrente y parecía no tener fin, la audaz forma de pensar con rapidez un dato nuevo que hiciera crecer la historia parecía nato en ellos. Cuando la miss Margarita concluyó la entrevista, pasamos a conocer a los alumnos de $6^{\circ}$ " $\mathrm{A}$ ".

Nuevamente la miss Margarita se encargó de hacer la entrevista con la profesora, nosotras nos encargamos de las actividades con el grupo, en esta ocasión en lo personal fue más complicado, ya que había más alumnos y el bullicio, la dispersión y desinterés eran desmedidos, pero a pesar de ello el grupo se prestó a participar en las dos actividades. En la primera se les dio un límite de tiempo cronometrado y se les pidió que utilizaran mínimo cinco figuras, en total fueron tres rondas en donde ambos equipos tuvieron el error de

En la segunda actividad salieron los dos equipos a contar la historia, en el equipo de los dos en donde estuvimos Chantal y Margarita, el grupo enlazó de manera adecuada la historia pero a pesar de ello, solían distraerse con cualquier comentario en doble sentido o simplemente la interpretación era distinta a lo que sus compañeros trataban de expresar. Algo que llamó mucho mi atención es que la mayoría ya se encuentra inmerso en las redes sociales, hablaban de Facebook y demás, pero sentí un orgullo que salió de la nada cuando un chico expresó que la mayoría de las redes sociales hacen perder el tiempo que se puede invertir e actividades provechosas. Sin darme cuenta, la actividad ya no era la de contar una historia, sino expresar una realidad que está afectando a la sociedad en la actualidad.

A las 12:45 horas los alumnos regresaron al salón, ahí fue cuando supimos que no tendrían clases al otro día, fue una tristeza ya que es un grupo que ya denota rasgos adolescentes muy marcados y hubiera sido una oportunidad increíble ver a través de sus palabras el panorama de su vida y cómo las experiencias fueron marcando su infancia, concretándose en el siguiente peldaño de su vida.

A la una en punto la miss Margarita, Chantal y Margarita acudieron al grupo de $4^{\circ}$ " $\mathrm{B}$ " para hacer el grupo focal de los padres de familia y por otro lado Esly y Yury asistieron a los sextos a realizar el grupo focal.

Con los padres de cuarto " $\mathrm{B}$ ", fue una experiencia enriquecedora, ver a través de sus ojos la preocupación sobre un futuro incierto y una actualidad que ahorca lentamente el presente. Sus rostros desconcertados, algunos hastiados, presurosos, pero a pesar de ello interesa- 
dos por las almas que la vida les ha puesto en sus manos. Se quedaron a escuchar las preguntas que teníamos que hacerles. Fue algo gracioso, pero al igual que los niños, la timidez gobernaba el aula y solo algunos padres se atrevían a hablar, expresar su sentir y sus preocupaciones, entre la multitud de mamás preocupadas, llamaron nuestra atención tres padres (varones) que iban entusiastas a recoger la boleta de sus hijos (a).

Sus palabras fueron concretas, sensatas, pero en sus ojos reflejaba la honestidad de cada una de las oraciones, la voz baja, el timbre similar al de su pequeño hijo, exclamó: lo importante es poder acompañar a nuestros hijos, ellos requieren de nuestro apoyo. Sus palabras, su esencia y lo que expresaba en silencio era suficiente para saber que él era el papá del orgulloso niño que vimos anteriormente. Sentí un vacío enorme, y mi mente en blanco comenzó a escribir un sinfín de cosas que quería decirle, poder felicitarlo por darle la felicidad más pura a una inocente alma, por enseñarle que la felicidad no está en las cosas materiales, sino en la enorme esencia del amor más puro que puede existir en este mundo: el de un padre a un hijo, a pesar de todas las emociones, para lo único que me dio fuerza $\mathrm{mi}$ corazón, fue una sonrisa y un nudo en la garganta, que tuvo que esperar hasta este momento para poder desaparecer.

Así fue nuestro día, los ojos profundos empañaron nuestras almas y las llenaron de gozo y felicidad, pero también de lágrimas, lo que desataba la bestia de la impotencia, la tristeza y el enojo, pero también alimentaron nuestro deseo de ser maestras, seguir empeñándonos en nuestra formación y querer siempre ayudarlos a salir adelante, tomarlos de la mano y curar sus heridas.

\section{Instrumentos}

\section{Entrevista a padres de familia de la Escuela Primaria Juan de la Barrera}

1. ¿Cuántos hijos/as tiene?
2. ¿A qué se dedica? (Oficio, ocupación)

3. ¿Qué grado de escolarización tiene?

4. ¿Cuáles son los principales problemas que enfrenta como padre de familia?

5. ¿Qué hace para resolver dichos problemas?

6. ¿De qué manera motiva a sus hijos/as para seguir estudiando? (Qué frases utiliza, incentivos, reforzadores)

7. Sus hijos/as, iqué problemas presentan sobre los estudios que realizan (estudiar la primaria)?

8. ¿Cómo lo/a apoya para resolverlos?

9. ¿De qué manera ayuda a sus hijos/as con las tareas o problemas que trae de la escuela?

10. ¿Qué importancia tiene para usted continuar los estudios superiores (universidad, postgrado, etc.)?

11. Su hijo/a (os/as) ipretende seguir estudiando? ¿De qué manera lo apoyará?

12. ¿De qué considera que depende que los niños/as sigan estudiando o trunquen sus estudios?

\section{Preguntas grupo focal con niños de la escuela} primaria Juan de la Barrera.

1. ¿Qué es lo que más te gusta de tus clases?

2. Da un ejemplo de cómo te enseña tu maestra.

3. Si pudieras decirle a tu maestra lo que te gustaría que hicieran en clase, ¿Qué sería?

4. Cuando tienes problemas en la escuela, itienes confianza para decirles a tus papás? Si es sí, ¿ellos Qué hacen?

5. ¿Cómo te animan o motivan tus papás?

6. ¿Qué quieres ser cuando seas mayor?

7. ¿Qué necesitas para lograr tus sueños?

8. ¿Qué te gustaría escuchar de tus papás? ¿Qué palabras quieres que te digan? 


\section{CATEGORÍAS}

\begin{tabular}{|c|c|c|c|}
\hline CATEGORÍAS & ENTREVISTA & GRUPO FOCAL ALUMNOS & GRUPO FOCAL PADRES \\
\hline $\begin{array}{l}\text { Enseñan- } \\
\text { za y } \\
\text { Aprendi- } \\
\text { zaje }\end{array}$ & $\begin{array}{l}\text { "La enseñanza es } \\
\text { crear andamios, } \\
\text { son los medios que } \\
\text { utiliza el maestro." } \\
\text { "Los niños no } \\
\text { tienen disposición } \\
\text { e interés aunque } \\
\text { me esfuerzo me he } \\
\text { desesperado" }\end{array}$ & 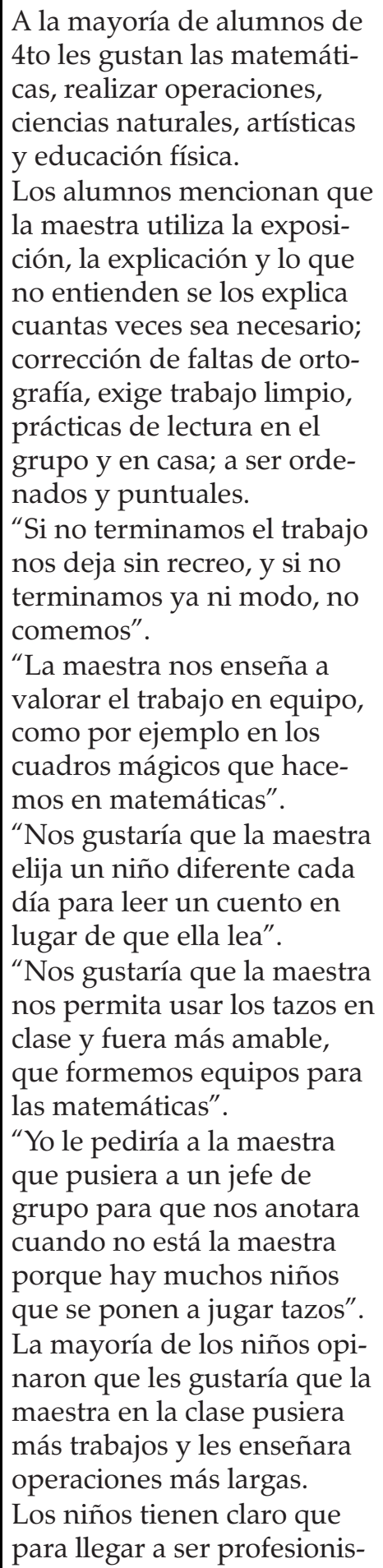 & \\
\hline
\end{tabular}




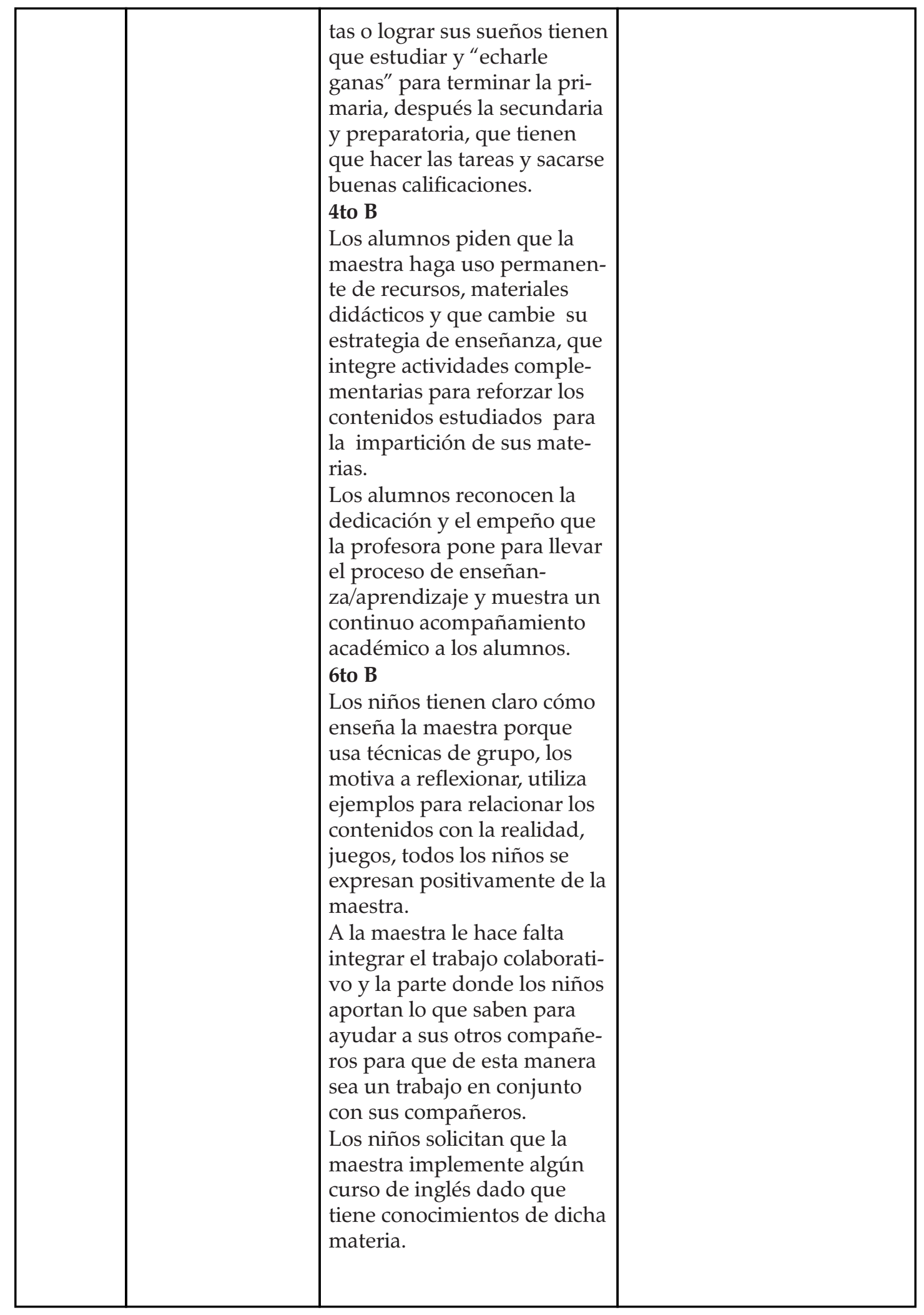




\begin{tabular}{|c|c|c|c|}
\hline CATEGORÍAS & ENTREVISTA & GRUPO FOCAL ALUMNOS & GRUPO FOCAL PADRES \\
\hline $\begin{array}{l}\text { Formación } \\
\text { de } \\
\text { maestros }\end{array}$ & 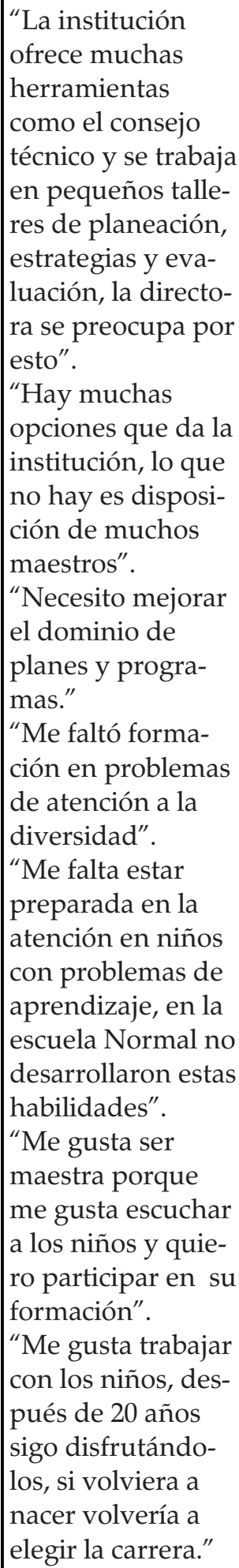 & & \\
\hline
\end{tabular}




\begin{tabular}{|c|c|c|c|}
\hline CATEGORÍAS & ENTREVISTA & GRUPO FOCAL ALUMNOS & GRUPO FOCAL PADRES \\
\hline $\begin{array}{l}\text { Prepara- } \\
\text { ción de los } \\
\text { padres }\end{array}$ & $\begin{array}{l}\text { “De } 27 \text { alumnos, } \\
\text { solo cinco de los } \\
\text { padres de familia } \\
\text { tienen preparación } \\
\text { ( } 2 \text { son maestros, } 2 \\
\text { son secretarias, } 1 \\
\text { es contador). Los } \\
\text { demás tienen nivel } \\
\text { secundario o pre- } \\
\text { paratorio. } \\
\text { "De los cinco } \\
\text { padres prepara- } \\
\text { dos, } 2 \text { hijos tienen } \\
\text { un buen nivel de } \\
\text { aprendizaje". } \\
\text { "Entre el 10\% y el } \\
20 \% \text { de padres } \\
\text { están preparados y } \\
\text { los hijos de esos } \\
\text { padres responden } \\
\text { muy bien en la } \\
\text { escuela". } \\
\text { "Sí influye la pre- } \\
\text { paración de los } \\
\text { padres, se observa } \\
\text { en su participa- } \\
\text { ción, en el cumpli- } \\
\text { miento del trabajo, } \\
\text { en el interés cuan- } \\
\text { do se les convoca } \\
\text { juntos a reunio- } \\
\text { nes." }\end{array}$ & $\begin{array}{l}\text { 4to B } \\
\text { La mayoría de los padres son } \\
\text { comerciantes o trabajan en el } \\
\text { campo o son empleados de } \\
\text { tiendas. } \\
\text { 6to B } \\
\text { Algunos de los padres solo } \\
\text { terminaron su educación } \\
\text { primaria y uno de los } \\
\text { alumnos que estaba en el } \\
\text { grupo focal mencionó que su } \\
\text { madre no había terminado la } \\
\text { primaria. }\end{array}$ & $\begin{array}{l}\text { 4to. B } \\
\text { "Las materias ahora ya vie- } \\
\text { nen muy diferentes que cuan- } \\
\text { do nosotros estudiábamos y } \\
\text { es difícil ayudarles o explicar- } \\
\text { les y son problemas que tene- } \\
\text { mos nosotros de prepara- } \\
\text { ción". } \\
\text { "Desgraciadamente en mi } \\
\text { educación hubo muchas } \\
\text { fallas y pasé mi primaria sin } \\
\text { saber muchas cosas que } \\
\text { ahora he ido analizando, yo } \\
\text { llegué con muchos trabajos } \\
\text { hasta la preparatoria y deseo } \\
\text { que mi hija llegué hacer lo } \\
\text { que le gusta o por lo menos } \\
\text { que llegue hasta la preparato- } \\
\text { ria, es bien padre hacer la } \\
\text { dinámica de las tareas y así } \\
\text { aprendemos juntas". } \\
\text { "Me preguntas acerca de tu } \\
\text { tarea y yo ni siquiera sé, tú } \\
\text { sabes más que yo". } \\
\text { Un gran porcentaje de padres } \\
\text { son comerciantes, tanto papá } \\
\text { como mamá y no están con } \\
\text { sus hijos porque trabajan } \\
\text { sábado y domingo. } \\
\text { "Yo trabajo los fines de sema- } \\
\text { na porque necesitamos dine- } \\
\text { ro, a veces lo económico es lo } \\
\text { que nos hace decidir". } \\
\text { Hubo cuatro padres que les } \\
\text { costaba trabajo hablar, eran } \\
\text { tímidos y hablaban muy que- } \\
\text { dito. } \\
\text { 6to B } \\
\text { Las } 6 \text { madres que asistieron al } \\
\text { grupo focal se dedicaban a } \\
\text { ser amas de casa y comercian- } \\
\text { tes. } \\
\text { Todas terminaron la primaria } \\
\text { y una la estaba cursando y } \\
\text { dos terminaron la secundaria. }\end{array}$ \\
\hline
\end{tabular}




\begin{tabular}{|c|c|c|c|}
\hline CATEGORÍAS & ENTREVISTA & GRUPO FOCAL ALUMNOS & GRUPO FOCAL PADRES \\
\hline $\begin{array}{l}\text { Apoyo de } \\
\text { padres }\end{array}$ & $\begin{array}{l}\text { "Es fundamental } \\
\text { la actitud de los } \\
\text { padres, porque el } \\
\text { logro de los alum- } \\
\text { nos se reduce a un } \\
30 \% \text { sin el apoyo } \\
\text { de los padres". } \\
\text { "No estoy satisfe- } \\
\text { cha con el apren- } \\
\text { dizaje de los alum- } \\
\text { nos, porque pla- } \\
\text { neo y no se da, } \\
\text { creo que el proble- } \\
\text { ma es por los } \\
\text { papás". } \\
\text { "En San Nicolás, } \\
\text { los padres que son } \\
\text { agricultores si } \\
\text { apoyaban a sus } \\
\text { hijos y los de aquí, } \\
\text { que son en su } \\
\text { mayoría comer- } \\
\text { ciantes no exigen a } \\
\text { sus hijos, no se } \\
\text { comprometen con } \\
\text { la educación de } \\
\text { sus hijos". } \\
\text { "El día que se dijo } \\
\text { que se darían úti- } \\
\text { les nadie faltó, en } \\
\text { cambio cuando } \\
\text { tienen que venir a } \\
\text { platicar de sus } \\
\text { hijos no vienen." } \\
\text { "En la escuela hace } \\
\text { falta apoyo de los } \\
\text { padres de familia } \\
\text { ya que no tienen } \\
\text { visión, solo los } \\
\text { mandan para que } \\
\text { estén entreteni- } \\
\text { dos". "Ya no hay } \\
\text { cultura porque la } \\
\text { comunidad se ha } \\
\text { formado con per- } \\
\text { sonas que vienen }\end{array}$ & $\begin{array}{l}\text { La mayoría de niños de 4to A } \\
\text { opinan que si ellos se encon- } \\
\text { traran ante un problema sus } \\
\text { padres hablarían con la maes- } \\
\text { tra primero para resolverlo. } \\
\text { Asimismo dijeron que sus } \\
\text { problemas son de bullying } \\
\text { porque los molestan o se } \\
\text { burlan de ellos. } \\
\text { "Si nos mandaron un recado } \\
\text { a nuestros papás, un recado } \\
\text { hay que enseñárselo y no } \\
\text { arrancar las hojas, porque por } \\
\text { decir mentiras nos pegan" } \\
\text { "Cuando estaba en kínder } \\
\text { una niña me pegaba y no le } \\
\text { decía a mi mamá pero un día } \\
\text { me encontró un moretón y le } \\
\text { tuve que decir a mi mamá y } \\
\text { fue a hablar con la maestra, } \\
\text { antes no le decía nada porque } \\
\text { casi nunca estaba conmigo". } \\
\text { "No les decimos a nuestros } \\
\text { papás lo que nos pasa porque } \\
\text { no tenemos la suficiente con- } \\
\text { fianza, pero ya que se lo deci- } \\
\text { mos es demasiado tarde". } \\
\text { "Mi papá me encontró unos } \\
\text { moretones, unos niños me } \\
\text { pegaban y no sabía quiénes } \\
\text { eran pero una vez me armé } \\
\text { de valor y le empecé a decir a } \\
\text { mi mamá y a mi papá lo que } \\
\text { pasaba". } \\
\text { "No hay que tener miedo con } \\
\text { los papás, hay que decirles la } \\
\text { verdad de lo que nos pasa". } \\
\text { Un gran porcentaje de los } \\
\text { niños del grupo de 4to A - } \\
\text { Esperan ser reconocidos por } \\
\text { sus padres, otros sufren la } \\
\text { ausencia de los mismos, unos } \\
\text { más manifiestan violencia } \\
\text { intrafamiliar al grado de que } \\
\text { en unos de los casos el padre } \\
\text { abandonó a la familia. }\end{array}$ & $\begin{array}{l}\text { 4to B } \\
\text { Algunos padres mencionaron } \\
\text { que para apoyar a sus hijos } \\
\text { en sus tareas era necesario } \\
\text { organizarse. } \\
\text { “Hay que optimizar el tiempo } \\
\text { para dar un tiempo de cali- } \\
\text { dad y no de cantidad a nues- } \\
\text { tros hijos". } \\
\text { Una minoría de padres traba- } \\
\text { ja todo el día y no pueden } \\
\text { acompañar a sus hijos, y solo } \\
\text { les dejan indicaciones y órde- } \\
\text { nes pensando que estos las } \\
\text { van a cumplir. } \\
\text { Dos mamás dieron a conocer } \\
\text { que son padre y madre y por } \\
\text { tanto tienen que trabajar para } \\
\text { sostener a su familia, y por } \\
\text { eso no están todo el tiempo } \\
\text { con sus hijos. } \\
\text { "Aunque yo no esté con uste- } \\
\text { des, allí tienen libros, pueden } \\
\text { buscar información en lo que } \\
\text { yo llego, si yo no estoy bus- } \\
\text { quen formas, no esperen a } \\
\text { que yo esté" } \\
\text { Algunos papás mencionaron } \\
\text { que sus hijos les reclaman su } \\
\text { atención y su tiempo pero } \\
\text { ellos no pueden porque están } \\
\text { trabajando. } \\
\text { "Yo creo que cuando mi hija } \\
\text { me pide que la apoye, tengo } \\
\text { que dejar lo que estoy hacien- } \\
\text { do y apoyarla y aprendamos } \\
\text { juntas". } \\
\text { Consideran que cuando los } \\
\text { jóvenes truncan sus estudios } \\
\text { es porque no recibieron } \\
\text { apoyo de los padres. } \\
\text { "Los niños no solamente } \\
\text { tienen que pensar a largo } \\
\text { plazo sino a corto, por ejem- } \\
\text { plo cuanto me voy esforzar } \\
\text { para obtener mejor califica- } \\
\text { ción en el siguiente bimestre" } \\
\text { 4to A } \\
\text { Se presentaron 19 personas } \\
\text { La mayoría de padres (varo- } \\
\text { nes) no puede dedicarles } \\
\text { tiempo a sus hijos porque } \\
\text { tienen un horario de trabajo }\end{array}$ \\
\hline
\end{tabular}




\begin{tabular}{|c|c|c|}
\hline $\begin{array}{l}\text { de otros lados, se } \\
\text { están perdiendo } \\
\text { tradiciones y cos- } \\
\text { tumbres". } \\
\text { "Cuesta trabajo } \\
\text { llevar a cabo el } \\
\text { modelo de compe- } \\
\text { tencias porque los } \\
\text { padres no partici- } \\
\text { pan, dicen que } \\
\text { apoyan a sus hijos } \\
\text { y es mentira, por } \\
\text { ejemplo a quienes } \\
\text { se les deja leer y } \\
\text { tienen que firmar } \\
\text { los padres para } \\
\text { garantizar que sí } \\
\text { se hizo, los padres } \\
\text { prefieren no per- } \\
\text { der el tiempo y les } \\
\text { ponen la firma sin } \\
\text { leer". } \\
\text { "Los padres casi } \\
\text { regañan al maes- } \\
\text { tro, no hay entrega } \\
\text { hacia la mejora de } \\
\text { sus hijos." }\end{array}$ & $\begin{array}{l}\text { 4to B } \\
\text { Algunos niños consideran } \\
\text { que para el cumplimiento de } \\
\text { sus sueños necesitan el apoyo } \\
\text { de sus padres en muestras de } \\
\text { afecto. } \\
\text { Las sugerencias de los padres } \\
\text { influyen en las decisiones de } \\
\text { sus posibles profesiones en el } \\
\text { futuro. } \\
\text { Los niños no reciben recono- } \\
\text { cimiento de parte de sus } \\
\text { papás y muchos manifesta- } \\
\text { ban la necesidad del apoyo y } \\
\text { del afecto. } \\
\text { Los padres de la mayoría de } \\
\text { los niños reciben un reforza- } \\
\text { miento verbal motivándolos a } \\
\text { continuar con sus estudios, } \\
\text { dándoles testimonio sobre } \\
\text { sus historias personales e } \\
\text { invitándolos a no repetirla y } \\
\text { que se esfuercen por estudiar. } \\
\text { 6to B } \\
\text { Los niños consideran que } \\
\text { necesitan el apoyo económico } \\
\text { de sus padres para poder } \\
\text { lograr sus sueños y llegar a } \\
\text { tener una profesión. } \\
\text { El apoyo que les hace falta a } \\
\text { los niños es moral y afectivo } \\
\text { ya que muchos se sienten } \\
\text { necesitados de palabras posi- } \\
\text { tivas y motivadoras que con- } \\
\text { tengan el reconocimiento de } \\
\text { sus habilidades. } \\
\text { Algunos niños comentaron } \\
\text { que si reciben el apoyo de sus } \\
\text { padres y eso les permite tener } \\
\text { seguridad en si mismos. } \\
\text { Algunos niños no tienen la } \\
\text { suficiente confianza para } \\
\text { hablar de sus problemas con } \\
\text { sus papás porque tienen } \\
\text { miedo hacia la reacción de } \\
\text { que estos puedan tener. Sin } \\
\text { embargo, la mayoría de los }\end{array}$ & $\begin{array}{l}\text { de casi } 12 \text { horas diarias o se } \\
\text { dedican al comercio trabajan- } \\
\text { do todo el día. } \\
\text { Hay dos madres que no ter- } \\
\text { minaron ni la primaria y se } \\
\text { sienten incapaces para apo- } \\
\text { yar a sus hijos. } \\
\text { "No puedo apoyarle mucho a } \\
\text { mi hijo porque por decir me } \\
\text { pregunta las tareas o algún } \\
\text { trabajo y no le puedo ayudar } \\
\text { porque no sé leer, ése es el } \\
\text { problema, lo he resuelto por } \\
\text { medio de mis otros niños, } \\
\text { ellos ayudan a sus hermani- } \\
\text { tos". } \\
\text { Solo hay una maestra la cual } \\
\text { no puede apoyar a sus hijos } \\
\text { por su trabajo. } \\
\text { Cuatro de las madres presen- } \\
\text { tes comentaron que su traba- } \\
\text { jo es hasta muy tarde y esto } \\
\text { no les permite apoyarlos en } \\
\text { sus tareas, no cuentan con } \\
\text { una pareja que les ayude en } \\
\text { la atención de los hijos. } \\
\text { “No tengo un horario fijo, } \\
\text { regreso hasta muy tarde, es } \\
\text { un poquito complicado". } \\
\text { Cinco madres jóvenes se } \\
\text { encontraban en el grupo, de } \\
\text { las cuales tres son madres } \\
\text { solteras y padecen en lo eco- } \\
\text { nómico, por lo que tienen } \\
\text { que trabajar desatendiendo a } \\
\text { sus hijos. } \\
\text { "Para mí el problema es el } \\
\text { apoyo económico, la falta de } \\
\text { figura paterna, yo soy papá y } \\
\text { mamá, soy madre soltera, yo } \\
\text { siempre le he dicho a mi hija: } \\
\text { tú tienes que salir adelante". } \\
\text { "Yo tengo a mi mamá que me } \\
\text { dice hazle así o hazle acá, es } \\
\text { lo que realmente a mí me ha } \\
\text { ayudado mucho". } \\
\text { Cuatro mamás tienen más de } \\
\text { tres hijos y cuentan con el } \\
\text { apoyo de su esposo lo cual les } \\
\text { permite cumplir con lo que la } \\
\text { escuela exige de los padres. } \\
\text { Se presentaron cuatro padres } \\
\text { (varones) lo cual es notorio, } \\
\text { dado que trabajan y casi nunca } \\
\text { responden a las convocatorias }\end{array}$ \\
\hline
\end{tabular}




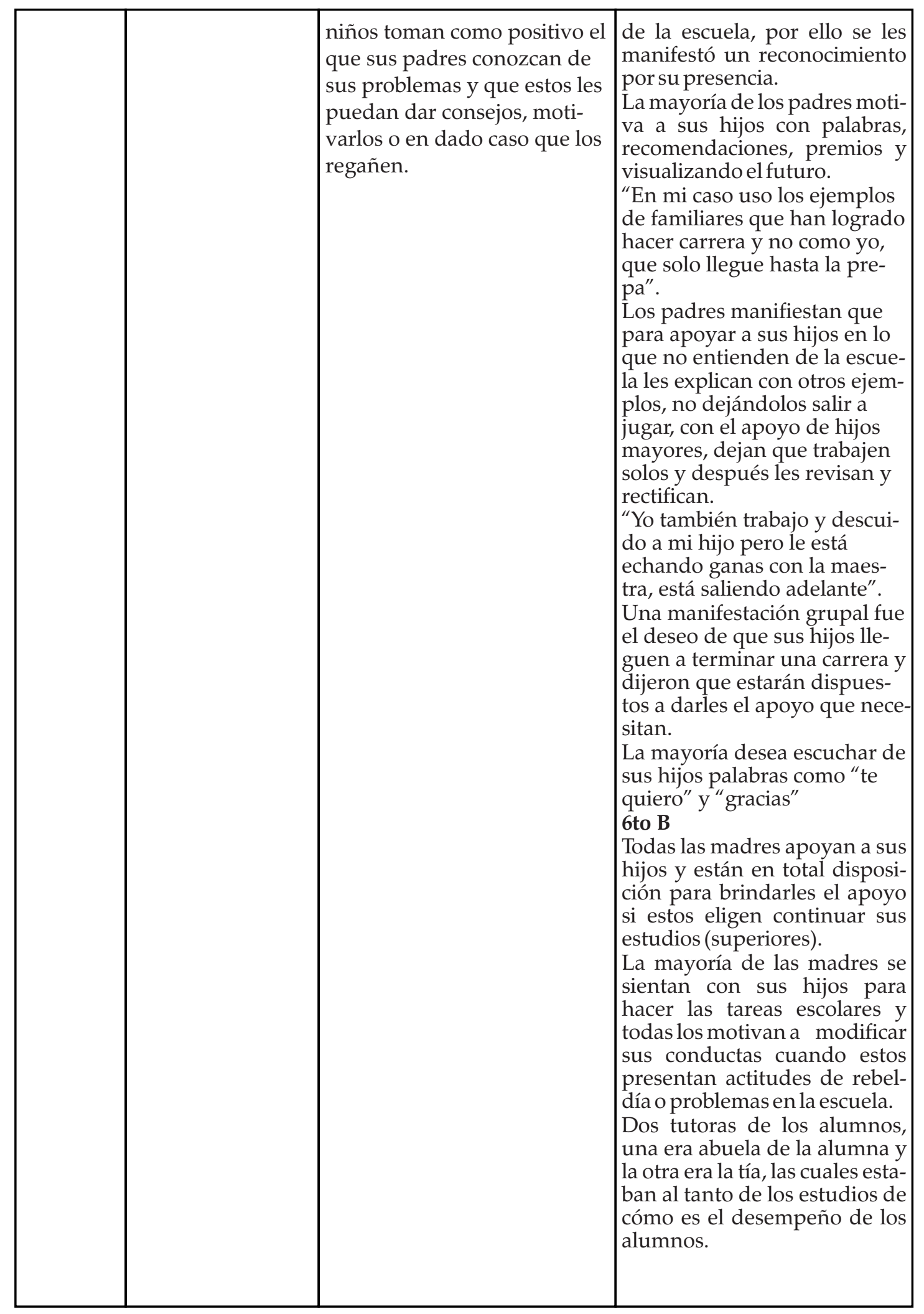




\begin{tabular}{|c|c|c|c|}
\hline CATEGORÍAS & ENTREVISTA & GRUPO FOCAL ALUMNOS & GRUPO FOCAL PADRES \\
\hline $\begin{array}{l}\text { Observa- } \\
\text { ciones }\end{array}$ & & $\begin{array}{l}\text { La mayoría de varones del } \\
\text { grupo de 4to A tienen aspira- } \\
\text { ciones de menos nivel acadé- } \\
\text { mico (bombero, policía, alba- } \\
\text { ñil, militar) que las niñas, las } \\
\text { cuales pretenden llegar a ser } \\
\text { profesionistas (doctoras, } \\
\text { maestras, veterinarias, enfer- } \\
\text { meras). Solo tres varones } \\
\text { expresaron que desean ser } \\
\text { médicos y uno dijo que maes- } \\
\text { tro. }\end{array}$ & $\begin{array}{l}\text { 4to B } \\
\text { La mayoría de padres consi- } \\
\text { deran que cuando sus hijos } \\
\text { lleguen a niveles medio supe- } \\
\text { rior sería importante conse- } \\
\text { guir becas para que puedan } \\
\text { concluir sus estudios. } \\
\text { Los padres esperan que sus } \\
\text { hijos les lleguen a decir "gra- } \\
\text { cias por lo que has hecho por } \\
\text { mí, o escuchar la frase" te } \\
\text { quiero", una mamá mencio- } \\
\text { nó que su hijo le dice "que le } \\
\text { ponga más atención". } \\
\text { Una más dijo con gusto que } \\
\text { su hija le dice que está muy } \\
\text { "orgullosa de ella". } \\
\text { Con lágrimas en los ojos una } \\
\text { madre mencionó que su hija } \\
\text { le dijo "que no la cambiaría } \\
\text { por nada en el mundo" y } \\
\text { "que soy la mejor mamá", } \\
\text { por lo menos la mitad de } \\
\text { madres asistentes deseaba } \\
\text { escuchar que sus hijos les } \\
\text { dieran noticias de que saca- } \\
\text { ban mejores calificaciones o } \\
\text { queles fue bien en la escuela. }\end{array}$ \\
\hline
\end{tabular}




\section{Conclusiones}

A lo largo de esta jornada de investigación que se realizó del 12 al 15 de noviembre de 2013, a partir de los supuestos considerados al inicio de esta investigación, se puede concluir que el nivel de formación de los maestros tiene un impacto trascendental en cómo el alumno aprende. Se pudo observar en dos momentos: el primero se basó en la realización del grupo focal con tres grupos, dos de cuarto y uno de sexto, en donde las preguntas sustentaron que la metodología que emplea el docente en sus clases los ayuda a concebir el conocimiento y concretarlo de manera significativa, lo percibimos al momento en que los alumnos de $4^{\circ}$ " $\mathrm{B}$ " pasaron a representar la forma en que la maestra da clases, a recordar los contenidos que la docente les había enseñado dos clases anteriores; la forma en que ellos se expresaron de sus temas de interés demostraron que se encontraban sincronizados con los temas escolares, por ejemplo un niño contestó que le interesaban los proyectos de matemáticas y de ciencias naturales, pues recordó que hace dos semanas habían realizado un germinado de frijoles y que diariamente lo había ido a cuidar; por otro lado no nos encontramos con ninguna respuesta que se enfocara a programas televisivos o de algún personaje de la farándula, ya que estos tienden a tener un impacto fuerte en los infantes y son tópicos que sacan en sus conversaciones. También los alumnos sugirieron que la profesora utilice otras estrategias para motivar a los alumnos, por ejemplo en la lectura y en la resolución de problemas matemáticos para que lleven un tinte más vivencial a su realidad.

Por otro lado en las entrevistas que se utilizaron con los docentes, se llega a la conclusión que entre el curriculum real y el formal hay una incongruencia en lo que respecta a la formación docente, específicamente lo apreciamos en la confusión que tienen entre lo que es aprendizaje, estrategias de aprendizaje y enseñanza, podrían parecer conceptos teóricos que no trascienden en el aula, sin embargo son el principio del proceso de enseñanza y aprendizaje que lleva el alumno. En el segundo supuesto, se llegó a la conclusión que el nivel educativo que tienen los padres de familia sí afecta en su aprendizaje, pero que también influye el acompañamiento de los padres con los hijos. Se pudo llegar a esta conclusión a través de los grupos focales realizados con los padres de familia y de los alumnos.
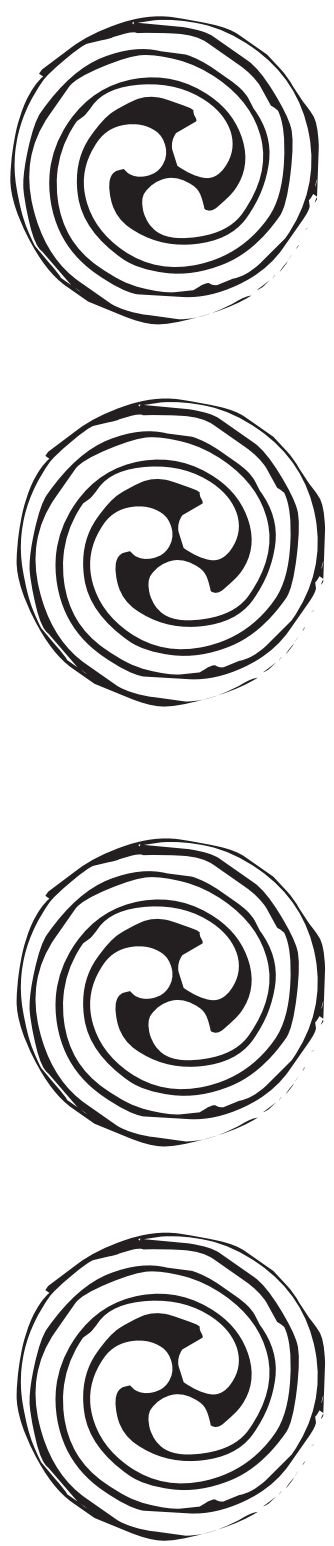


\section{Fuentes de consulta:}

Ausubel, D., Novak, J. y Hanesian, H. (2005). Psicología educativa: un punto de vista cognoscitivo. México: Ed. Trillas.

Bazán, A; Zavala, A; López, M. y Barona, C. (2006). Relación entre indicadores de formación del maestro, conocimiento de planes y programas de enseñanza, y el desempeño de escolares en evaluaciones de lengua escrita. Revista Latinoamericana de Estudios Educativos. México: Vol. XXXVI (Núm. 1-2). Págs. 75-93.

Beltran, J, Álvarez, J. (1995). Psicología de la Educación. España: Editorial Boixareu.

Coll, C. (2009). Localización: Infancia y Aprendizaje. España: Journal for the Study of Education and Development, № 41, págs. 131-142.

García, Y. y Mendoza, B. (2009). El autoritarismo y su expresión en la formación docente. México: Laurus, vol.15 (núm.30). págs. 71-93.

Gordon H. Bower, Ernest R. Hilgard. (2000). Teorías del aprendizaje. México. Trillas.

Hernández, P. (2002). Psicología de la educación: corrientes actuales y teorías aplicadas. México: Ed. Trillas.

Herraiz, M. (1999). Formación de Formadores.Manual Didáctico. México. Editorial Limusa.

Matute, E; Sanz, A; Gumá, E; Rosselli, M. y Ardila, A. (2009). Revista Latinoamericana de Psicología. Vol. 4 (núm.2).págs. 257-276.

Rodríguez, M. Zuñiga, M. y Guier M. (2002). Didáctica Ambiental. Costa Rica: Editorial la Universidad.

Rodríguez, A. Sánchez, S. Álvarez, M. y Rojas, B. (2008). La mediación, el acompañamiento y el aprendizaje individual. Revista Scielo.

Yárnoz, S. (2006). ¿Seguimos descuidando a los padres? El papel del padre en la dinámica familiar y su influencia en el bienestar psíquico de sus componentes. Anales de psicología. Vol.22 (núm. 2). Págs.175-185.

http://www.monografias.com/trabajos57/estrategias-aprendizaje/estrategiasaprendizaje2.shtml

http://dialnet.unirioja.es/servlet/articulo?codigo $=48298$.

http://www.unesco.org.ve/index.php?option $=$ com_content\&view $=$ article\&id $=2768 \% 3 \mathrm{Aform}$ a cion-d oc en te-la-clave-para-lograr-un-verdadero-ca mbioeducativo\&catid $=126 \% 3$ Anoticias-pagina-nueva\&Itemid $=712 \&$ lang $=\mathrm{es}$
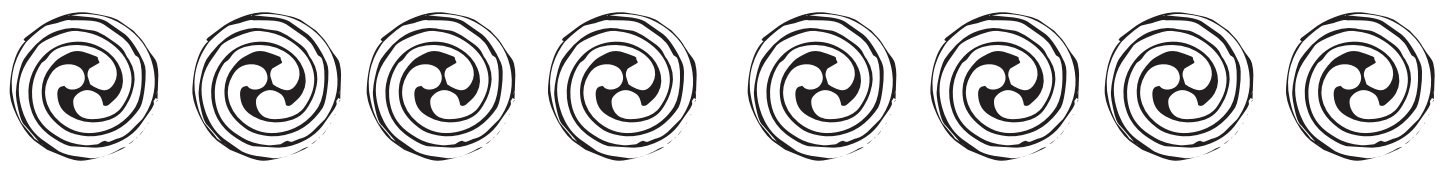

20) 29 


$$
\rho^{\infty}
$$

